\title{
First Record of Two Siriella Species of Mysids (Crustacea: Mysida) from the Korean Waters
}

\author{
Soo-Gun Jo* \\ Department of Marine Biotechnology, Kunsan National University, Kunsan 573-701, Korea
}

\begin{abstract}
Two pelagic species Siriella izuensis Murano and Fukuoka, 2008 and Siriella japonica Ii, 1964, are reported for the first time from the Korean waters, together with descriptions and illustrations. S. izuensis can be distinguished from its closest relative, Siriella japonica, by the normal inner flagellum of the antennule of males, as opposed to the swollen proximal part in $S$. japonica, and by the slightly more distinct tendency of alternate arrangement of spines on the distal third lateral margin of the telson than in $S$. japonica. S. izuensis and S. japonica differ distinctly from other related species by a combination of the triangular rostral plate, the moderate size of the eyes, the form and arrangement of the lateral spines of the telson, and six or seven graded spines on the distal outer margin of the uropodal exopod. A taxonomical key is given for the genus Siriella from the Korea waters.
\end{abstract}

Key words: Crustacea, Mysida, Siriella izuensis, Siriella japonica

\section{Introduction}

The genus Siriella Dana, 1850 is one of the largest groups of mysids, in which 77 species have been described to date. Among these, 62 species have been recorded from the warmwater region of the West Pacific Ocean and the Indian Ocean (Murano and Fukuoka, 2008). The Siriella species occur in shallow coastal waters as well as oceanic waters. So far, only five species of the genus Siriella have been reported from Korean waters (Ii, 1964; Jo et al., 1998).

During a recent survey in the Korean waters, Siriella izuensis Murano and Fukuoka, 2008 and Siriella japonica Ii, 1964 were collected. The present study briefly describes, with illustrations, the two additional species from the shallow coastal waters as the first record of Korean mysid fauna.

\section{Materials and Methods}

All specimens were collected using a light trap at night.
Collected mysids were immediately fixed in $10 \%$ buffered formalin solution on the shore and washed in distilled water before being preserved in the laboratory. Total length was measured from the tip of rostrum to the end of telson. Illustrations were made with the aid of a camera lucida under a microscope (Optiphot-2, Nikon, Japan). Images were also recorded with a digital camera (D5000, Nikon, Japan) under a dissecting microscope (SMZ-U, Nikon, Japan).

\section{Results and Discussion}

Order Mysida Haworth, 1825

Family Mysidae Haworth, 1825

Subfamily Siriellinae Norman, 1892

Genus Siriella Dana, 1850

(New Korean name: Na-seon-gon-jaeng-i-sok)
Received 13 February 2014; Revised 21 April 2014

Accepted 22 April 2014

*Corresponding Author

E-mail: sgjo@kunsan.ac.kr 


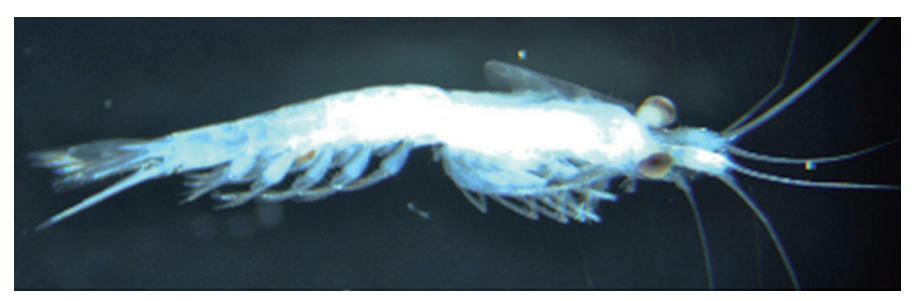

Fig. 1. Siriella izuensis Murano and Fukuoka, 2008; male, $7.5 \mathrm{~mm}$.

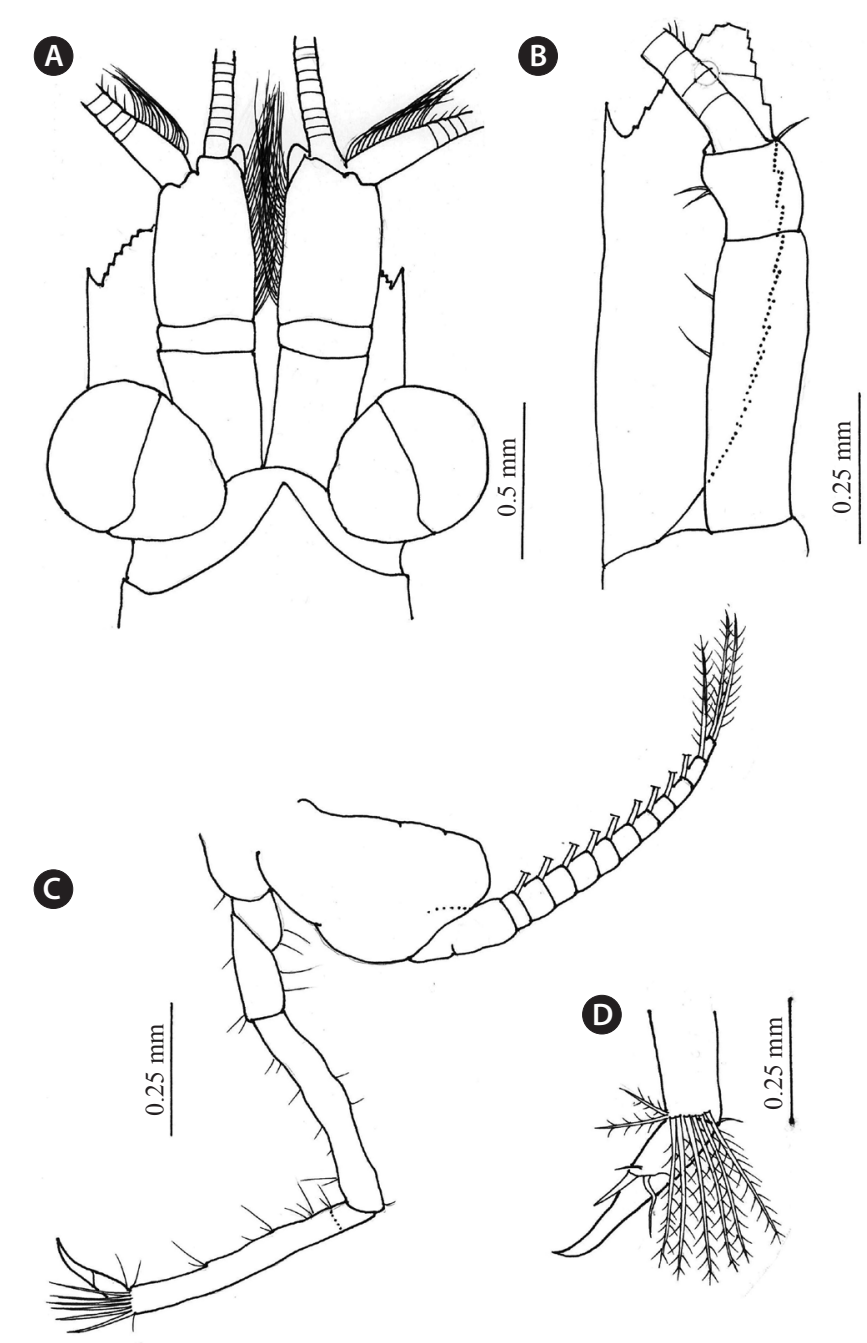

Fig. 2. Siriella izuensis Murano and Fukuoka, 2008; male. A, Anterior part of body; B, Antenna; C, D, Eighth thoracopod.

\section{Siriella izuensis Murano and Fukuoka, 2008}

(new Korean name: Jjal-beun-bu-ri-na-seon-gon-jaeng-i) (Figs. 1-3)

Siriella japonica var. izuensis Ii, 1964: 105-108, fig. 26; Liu and Wang, 2000: 102-104, fig. 20. (nomen nudum)

Siriella japonica var. sagamiensis Ii, 1964: 108-112, figs. 27, 28. (immature form)

Siriella japonica: Shen et al., 1989: 192-195, fig. 1.
Siriella japonica japonica: Liu and Wang, 2000: 101-102, fig. 19.

Siriella izuensis Murano and Fukuoka, 2008: 83-87, figs. 41, 42.

Type locality. Suruga Bay off Mera, Izu Peninsula, Japan.

Material examined. Seven adult males $(6.5-7.5 \mathrm{~mm})$, ten adult females (6.5-8.5 mm), 34 54' $0.25^{\prime \prime} \mathrm{N}, 128^{\circ} 27^{\prime} 21.62^{\prime \prime}$ E, Wonpyeong-ri, Yongnam-myeon, Tongyeong-Si, Gyeongsangnam-do, light trap, 29 September 2013, S.-G. Jo. 


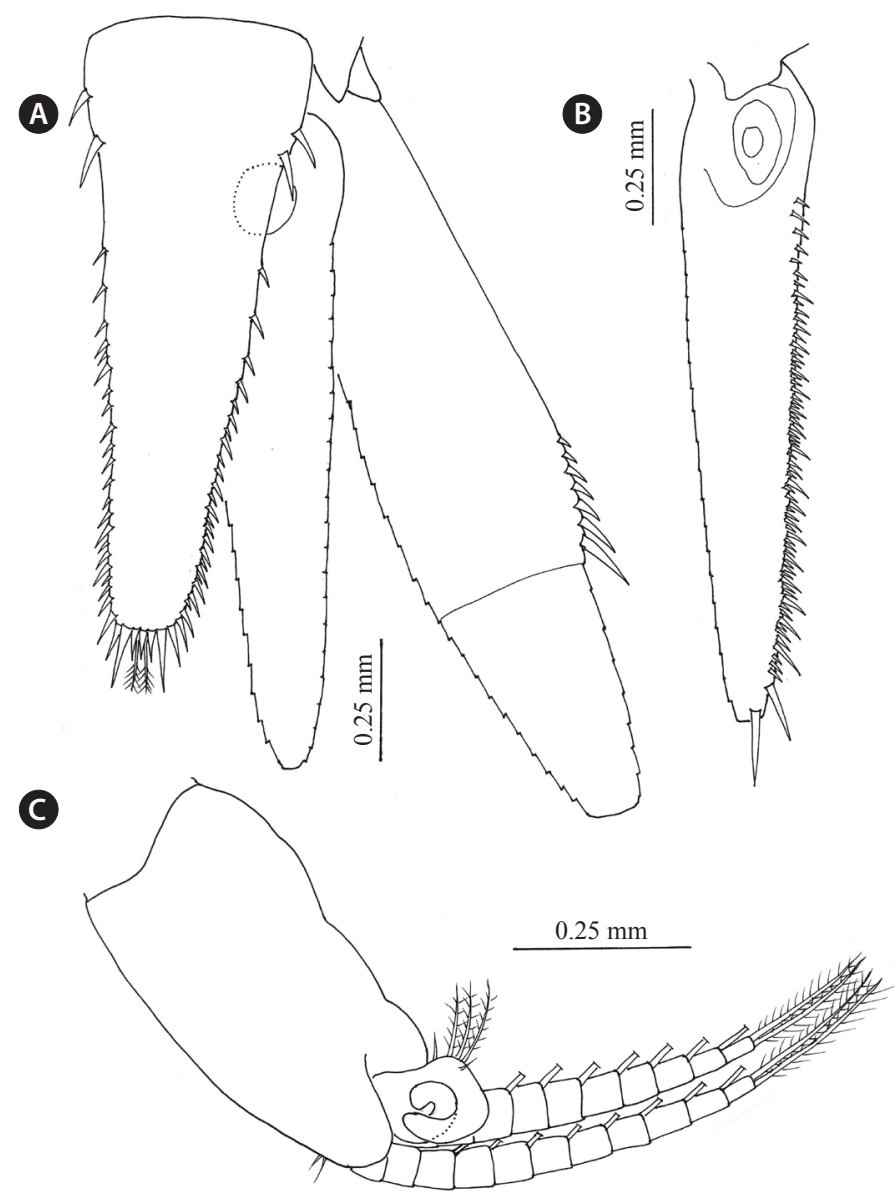

Fig. 3. Siriella izuensis Murano and Fukuoka, 2008; male. A, Telson and uropod; B, Uropod; C, D, Fourth pleopod.

Description. Body robust (Fig. 1). Anterior margin of carapace (Fig. 2A) produced into triangular rostral plate with slightly concave lateral margins. Anterior margin of cephalon rounded. Eyes (Fig. 2A) longer than broad, reaching distal margin of first segment of antennular peduncle; cornea occupying almost half of whole eye. Antennal scale (Fig. 2A and $2 B$ ) reaching $2 / 3$ of third segment of antennular peduncle, almost three times as long as broad; outer margin naked and terminating in a prominent spine extending beyond antennal peduncle; suture distinct. Antennular peduncle of male (Fig. 2A) stout; third segment almost same length as first; inner flagellum slender and not swollen at proximal part; appendix masculina with densely armed with sensory hairs. Endopod of third to eighth thoracic limbs (Fig. 2C and 2D) with a bent terminal claw; carpopropodus armed with terminal brush of setae on distal margin; exopod with 12-segmented flagellum. Pleopods of male (Fig. 3C) biramous, with spirally coiled pseudobranchial rami in second to fourth pairs and with straight ones in first and fifth pairs; both endopod and exopod 11-segmented. All setae normal. Endopod of uropod (Fig. 3A and $3 \mathrm{~B}$ ) extending beyond telson, densely armed with series of short and long spines along inner margin, spines increasing in size distally. Exopod of uropod two-jointed, extending beyond endopod, and armed with several graded spines occupying about $1 / 4$ of outer margin of proximal joint. Telson (Fig. $3 \mathrm{~A}$ ) about 2.7 times as long as broad at base; lateral margin armed with two larger spines proximally and alternating long and short spines distally; apex rounded, armed with a pair of setae and five spines, of which two outer ones much longer than three inner ones.

Remarks. Ii (1964) originally described this species as Siriella japonica var. izuensis before Murano and Fukuoka (2008) established a new species, S. izuensis. However, Ii's (1964) taxon is nomen nudum because infrasubspecific names such as "variety" or "form" are not available names (ICZN, 2000). After having reexamined multiple specimens from the coasts of Honshu, including Ii's collection, Murano and Fukuoka (2008) found that S. japonica var. izuensis was distinguished from $S$. japonica in the inner flagellum of the antennule and the arrangement in the lateral spines of the telson. The most critical distinction between them was that the flagellum was normal and slender in S. izuensis, while it was considerably swollen in the proximal part of the flagellum in S. japonica. They also differ from each other in the following points. In 


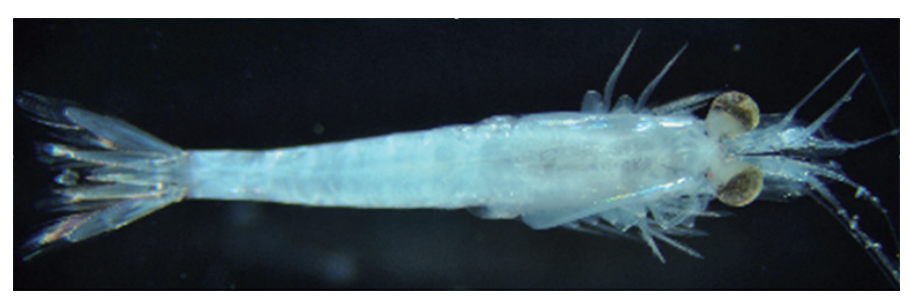

Fig. 4. Siriella japonica li, 1964; male, $6.7 \mathrm{~mm}$.

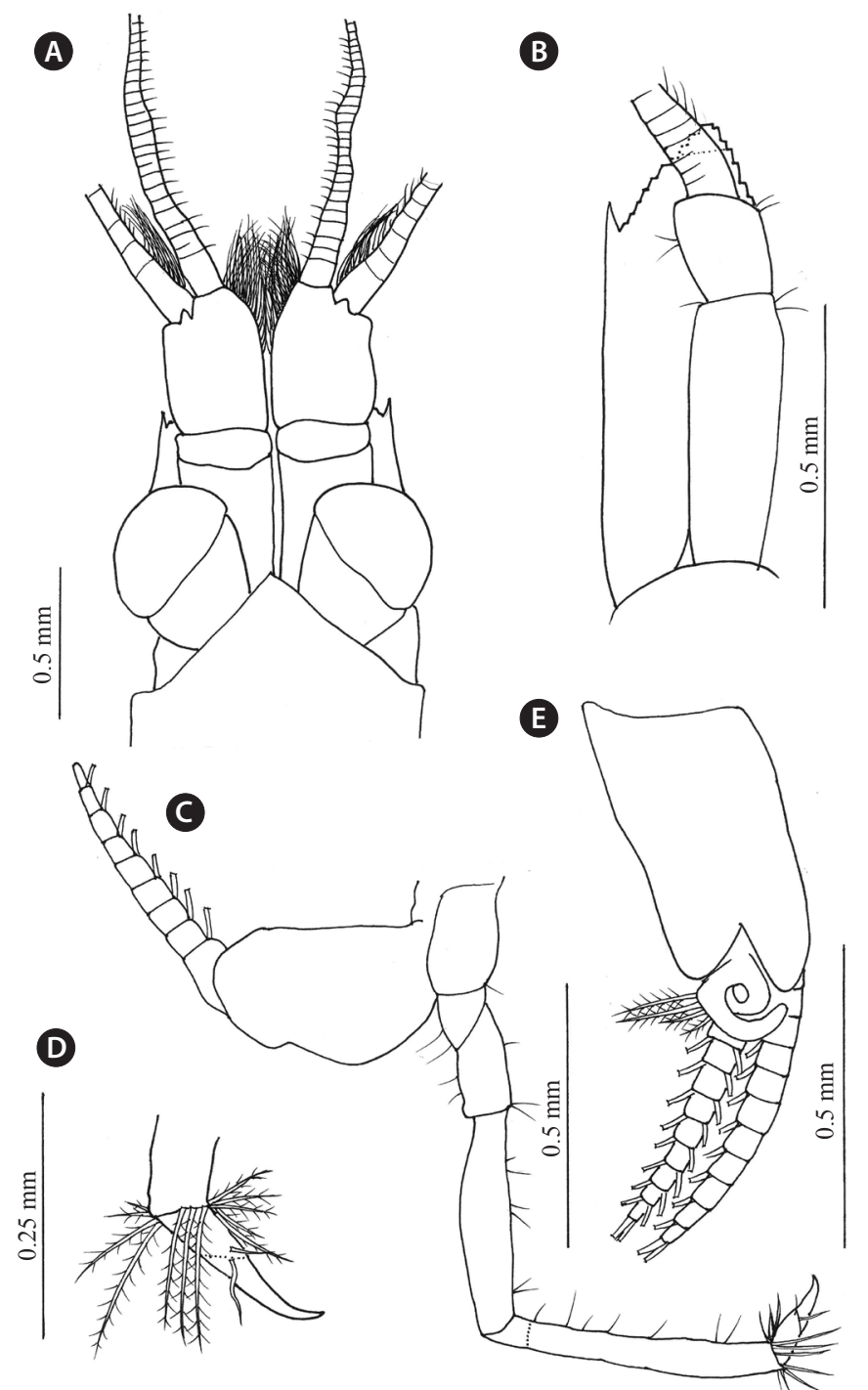

Fig. 5. Siriella japonica li, 1964; male. A, Anterior part of body; B, Antenna; C, D, Eighth thoracopod.

S. izuensis the rounded margin of cephalon is clearly visible beyond the rostral plate and the uropodal exopod has the graded spines occupying about one quarter of the outer margin of the proximal joint, while in $S$. japonica the anterior margin of cephalon is almost invisible because of the rostral plate and the graded spines occupies about one third of the outer margin. In $S$. izuensis the telson is about 2.7 times as long as broad at the base, compared to 2.8 times in S. japonica.
S. izuensis is very similar to S. okadai Ii, 1964 in many characters, but differs from the latter by having the rounded margin of cephalon clearly visible beyond the rostral plate. The present specimens agree well with the original description of Murano and Fukuoka (2008) in the main characteristics. This is the first record of S. izuensis from the coast of Korea.

Distribution. The South Sea in Korea (present study); the Yellow Sea, the Bohai Sea, and the South China Sea in China 


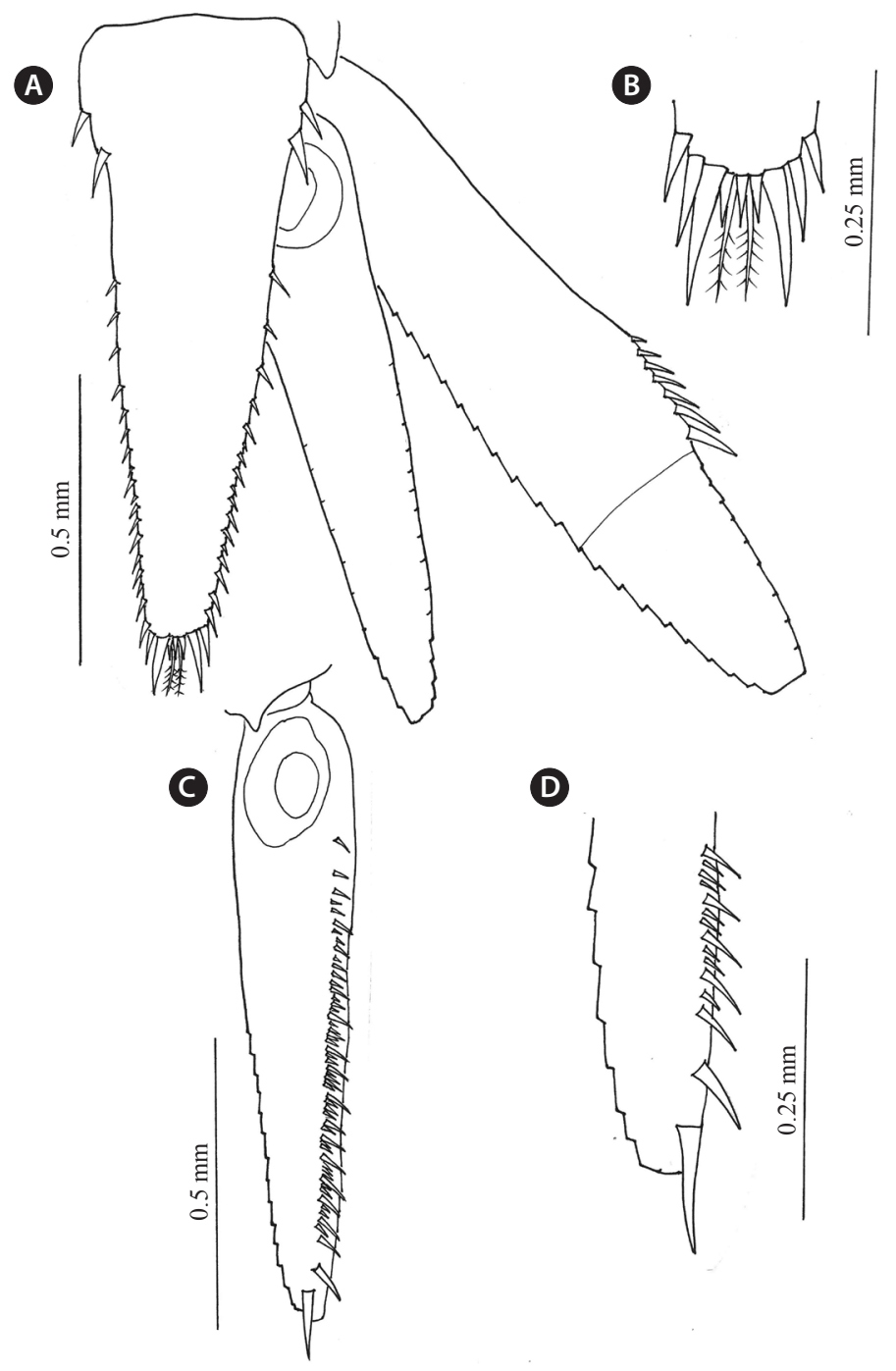

Fig. 6. Siriella japonica li, 1964; male. A, Telson and uropod; B, Telson; C, D, Uropod.

(Liu and Wang, 2000); coasts of the warm-water region of Honshu, Japan (Ii, 1964; Murano and Fukuoka, 2008).

\section{Siriella japonica li, 1964}

(new Korean name: Bu-eun-pyeon-mo-na-seon-gon-jaeng-i) (Figs. 4-6)

Siriella japonica Ii, 1964: 102-105, fig. 25; Mauchline and Murano, 1977: 76 [catalogue]

Not Siriella japonica: Shen et al., 1989: 192-195, fig. 1. (=Siriella izuensis)

Type locality. Port Oniwaki, Rishiri Island, Hokkaido, Japan.

Material examined. Two adult males $(7.0 \mathrm{~mm})$, three ovigerous females $(6.0 \mathrm{~mm})$, one adult female $(6.0 \mathrm{~mm})$, five immature males (4.0-5.1 mm), eight immature females (4.3-5.2 $\mathrm{mm}$ ), four juveniles (4.0 mm), 34 $52^{\prime} 25.12^{\prime \prime} \mathrm{N}, 128^{\circ} 28^{\prime}$
4.62" E, Jangpyeong-ri, Yongnam-myeon, Tongyeong-Si, Gyeongsangnam-do, light trap, 29 September 2013, S.-G. Jo; five immature females (5.0-5.2 mm), $37^{\circ} 57^{\prime} 15.89^{\prime \prime} \mathrm{N}, 124^{\circ}$ $44^{\prime} 16.19^{\prime \prime}$ E, Jinchon-ri, Baengnyeong-myeon, Ongjin-gun, Incheon, light trap, 23 October 2012, B. H. Kim.

Description. Body robust (Fig. 4). Anterior margin of carapace (Fig. 5A) produced into a broad triangular rostral plate with nearly straight lateral margins. Anterior margin of cephalon rounded but almost invisible because the rostral plate covers it. Eyes (Fig. 5A) slightly longer than broad, falling short of distal margin of first segment of antennular peduncle; cornea broad, occupying more than half of whole eye. Antennal scale (Fig. 5A and 5B) reaching two thirds of third segment of antennular peduncle, almost three times as long as broad; outer margin naked and terminating in a prominent spine almost reaching distal end of antennal peduncle; suture distinct. Antennular peduncle of male (Fig. 5A) stout; third segment 
almost same length of first; inner flagellum slender and slightly swollen at proximal part; appendix masculina with densely armed with sensory hairs. Endopod of third to eighth thoracic limbs (Fig. 5C and 5D) with a bent terminal claw; carpopropodus armed with terminal brush of setae on distal margin; exopod with nine-segmented flagellum. Pleopods of male (Fig. 5E) biramous, with spirally coiled pseudobranchial rami in second to fourth pairs and with straight ones in first and fifth pairs; both endopod and exopod 11-segmented. None of the setae modified. Endopod of uropod (Fig. 6A and 6C) slightly extending beyond telson, densely armed with series of short and long spines along inner margin, spines increasing in size distally. Exopod of uropod two-jointed, extending beyond endopod, and armed with several graded spines occupying about one third of outer margin of proximal joint. Telson (Fig. 6A) about 2.8 times as long as broad at base; lateral margin armed with two larger spines proximally to others and alternating long and short spines distally; apex rounded, armed with a pair of setae and five spines, of which two outer ones much longer than three inner ones.

Remarks. S. japonica resembles S. sinensis Ii, 1964 and Siriella koreana Murano and Fukuoka, 2008, but is easily distinguished from its relatives by a combination of the dilated inner flagellum of the male antennule, the short and broad rostral plate, and the arrangement of graded spines on the outer margin of uropodal exopod. The present specimens agree well with the original description of Murano and Fukuoka (2008) in the main characteristics. This is also the first record of $S$. japonica from the coast of Korea.

Distribution. The South Sea and Yellow Sea in Korea (present study); the Yellow Sea, the Bohai Sea, and the South China Sea in China (Liu and Wang, 2000); coasts of Honshu, Japan (Ii, 1964; Murano and Fukuoka, 2008).

\section{Key to the species of the genus Siriella from the Korean waters}

1. Uropodal endopod longer than exopod..............................2

- Uropodal endopod shorter than exopod.................................. 3

2. Rostral plate shortly pointed; cornea of eye occupying less than half of whole eye........................... gracilis Dana, 1852 - Rostral plate sharply elongated; cornea of eye greatly expanded, occupying almost half of whole eye.

..S. thompsoni (Milne-Edwards, 1837)

3. Inner flagellum of male antennule swollen in proximal part

- Inner flagellum of male antennule normal in proximal part

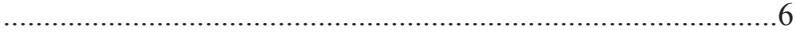

4. Inner flagellum of male antennule moderately swollen in proximal part; prominent spine on outer distal margin of antennal scale almost reaching distal end of antennal peduncle S. japonica Ii, 1964

- Inner flagellum of male antennule remarkably swollen in proximal part......
5. Prominent spine on outer distal margin of antennal scale falling short of distal end of antennal peduncle.

S. watasei Nakazawa, 1910

- Prominent spine on outer distal margin of antennal scale extending far beyond distal end of antennal peduncle.....

S. koreana Murano and Fukuoka, 2008

6 . Triangular rostral plate elongated, covering anterior margin of cephalon. S. okadai Ii, 1964

- Triangular rostral plate shortly pointed, not covering anterior margin of cephalon......S. izuensis Murano and Fukuoka, 2008

\section{Acknowledgments}

The author is grateful to two anonymous reviewers for improving the manuscript. This research was conducted under the National Marine Life Collection program sponsored by the Ministry of Oceans and Fisheries, Korea (MABIK 2012-00103-02).

\section{References}

Dana JD. 1850. Synopsis generum crustaceorum ordinis "Schizopoda". Am J Sci Arts Ser 2 9, 129-133.

Dana JD. 1852. United States Exploring Expedition during the years $1838,1839,1840,1841,1842$, under the command of Charls Wilkes, U.S.N., 13, Crustacea pt 1, C. Sherman, Philadelphia, USA.

Haworth AH. 1825. A new binary arrangement of the macrurous Crustacea. Philos Mag J 65, 183-184.

ICZN (International Commission on Zoological Nomenclature). 2000. International Code of Zoological Nomenclature. 4th ed. The International Trust for Zoological Nomenclature, London, GB.

Ii N. 1964. Fauna Japonica, Mysidae (Crustacea). Biogeogr Soc Japan Nat'l Sci Mus Tokyo.

Jo SG, Ma CW, Suh HL. and Hong SY. 1998. Mysidacea (Crustacea) from the Korea Strait and its adjacent waters. Korean J Biol Sci 2, 33-47.

Liu R and Wang S. 2000. Fauna Sinica. Arthropoda Crustacea Malacostraca, Order Mysidacea. Science Press, Beijing, CN.

Mauchline J and Murano M. 1977. World list of Mysidacea, Crustacea. J Tokyo Univ Fish 64, 39-88.

Milne-Edwards, H. 1837. Histoire naturelle des crustacés. 2, Roret, Paris, FR.

Murano M and Fukuoka K. 2008. A systematic study of the genus Siriella (Crustacea: Mysida) from the Pacific and the Indian Oceans, with descriptions of fifteen new species. Nat'l Mus Nature Sci Monographs, Nat'l Mus Nature Sci, Tokyo, JP.

Nakazawa K. 1910. Notes on Japanese Schizopoda. Annot Zool Jap 7, 247-261.

Norman AM. 1892. On British Mysidae, a family of Crustacea Schizopoda. Ann Mag Nat Hist 10, 143-166.

Shen CJ, Liu JY and Wang S. 1989. Mysidacea in waters off the north China coasts. Stud Mar Sinica 30,189-227. 